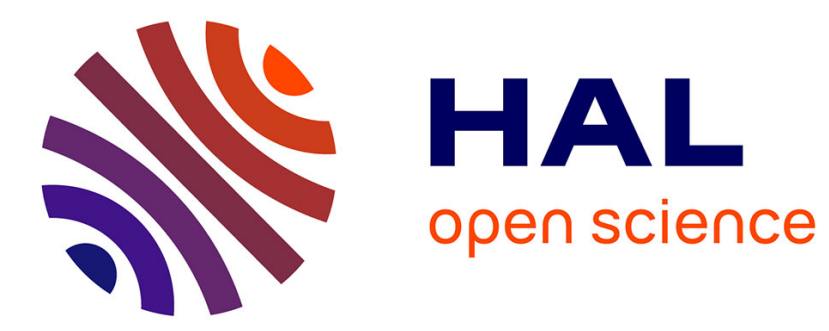

\title{
New pulsed photoacoustic technique for measuring absolute optical absorption coefficient
}

\author{
S. Egerev, L. Lyamshev, A. Pashin, A. Fokin
}

\section{To cite this version:}

S. Egerev, L. Lyamshev, A. Pashin, A. Fokin. New pulsed photoacoustic technique for measuring absolute optical absorption coefficient. Journal de Physique IV Proceedings, 1994, 04 (C7), pp.C7381-C7-384. 10.1051/.jp4:1994789 . jpa-00253320

\section{HAL Id: jpa-00253320 https://hal.science/jpa-00253320}

Submitted on 1 Jan 1994

HAL is a multi-disciplinary open access archive for the deposit and dissemination of scientific research documents, whether they are published or not. The documents may come from teaching and research institutions in France or abroad, or from public or private research centers.
L'archive ouverte pluridisciplinaire HAL, est destinée au dépôt et à la diffusion de documents scientifiques de niveau recherche, publiés ou non, émanant des établissements d'enseignement et de recherche français ou étrangers, des laboratoires publics ou privés. 


\title{
New pulsed photoacoustic technique for measuring absolute optical absorption coefficient
}

\author{
S.V. Egerev, L.M. Lyamshev, A.E. Pashin and A.V. Fokin \\ N.N. Andreev Acoustics Institute, 4 Shvernika Str., 117036 Moscow, Russia
}

\begin{abstract}
Pulsed photoacoustic spectroscopy (PAS) technique for measuring absolute optical absorption coefficient requiring no additional measurements is presented. It is based on determination of amplitude-time characteristics of PA signal generated in air surrounding sample under investigation. PA signal is excited by short laser pulse. Sample is placed in a three-chamber PA cell. Time dependence of PA signal expected in different chambers of PA cell is derived. Water absorption coefficient at IR wavelength was measured.
\end{abstract}

\section{INTRODUCTION}

For performing quantitative photoacoustic spectroscopy (PAS) it is desirable to have a method of obtaining the absolute optical absorption coefficient of a sample $\beta$ from PAS measurements alone. Such methods, using CW-optical radiation and gas-microphone scheme of registration, are described in Ref. [1,2]. Wetsel and McDonald [1] used the modulation frequency dependence of the PAS amplitude to obtain a value of $\beta$ by the comparison of the experimental data with the theoretical predictions of Rosencwaig and Gersho [3]. By measuring the PAS amplitude at a given wavelength over a frequency range between $200 \mathrm{~Hz}$ and $2 \mathrm{kHz}$ the authors were able to obtain a value of $\beta$ accurate to 10-15\%. Teng and Royce [2] proposed the method of measuring absolute optical absorption coefficient as a function of wavelength by combining amplitude and phase information obtained from the photoacoustic (PA) response. Only a single spectral scan at one modulation frequency is required and no auxiliary measurement of $\beta$ at a chosen wavelength is necessary.

We present a new pulsed PAS technique for measuring absolute optical absorption coefficient, based on determination of amplitude-time characteristics of PA signal, generated in air surrounding sample under investigation. It belongs to the methods of dynamic diagnostics previously introduced for PA applications with direct registration [4] which assumes, for example, the extraction of additional information offered by the relationship among the amplitudes of the phases of the fine structure of a signal. PA signal is excited by a short laser pulse. Sample is placed in lateral chamber of threechamber PA cell described in Ref. [5]. It was shown in Ref. [5] that utilising of such cell helps to overcome difficulties in registration and interpretation of pulsed PA signal caused by excitation of high frequency resonances. We use the two low-frequency resonances. First of these corresponds to in-phase air motion in the inter-chamber channels while the second one corresponds to opposite-phase air motion. 


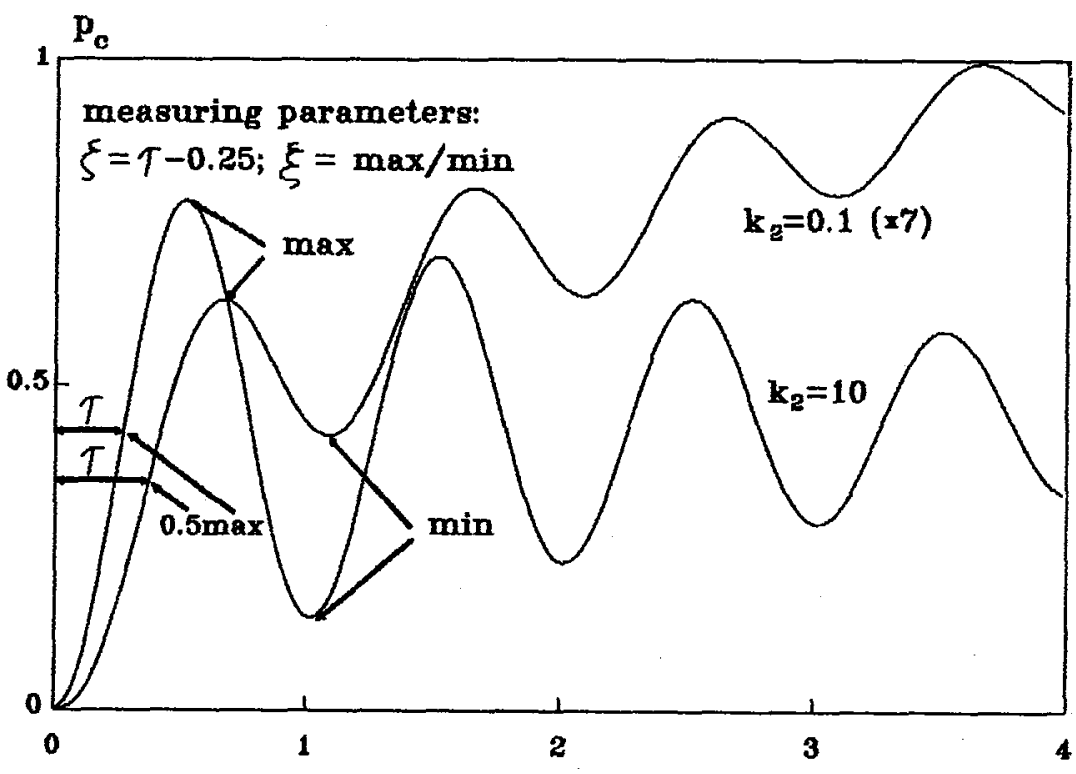

Figure 1: Calculated PA signal $p_{c}$ (a.u.) as a function of $t / T_{2}$ with $T_{2}=2 \pi / \omega_{2}$ for several values of parameter $k_{2}$. Here $Q_{2}=10$.

\section{THEORY}

We assume that duration of radiation pulse is small compared to period of air pressure oscillations in PA cell hence the spectrum of PA signal can be expressed as the product of sample transform function and that of the cell. The former is calculated according to thermal piston model [3], and the latter is derived using quasistatic adiabatic approximation [5]. For thermally thick sample and PA cell with high quality factor the inverse Fourier transform can be performed analytically. Corresponding expressions for PA signal expected in central chamber of PA cell $p_{c}$ and for difference of PA signals in central and lateral chambers $p_{d}$ are as follows:

$$
\begin{aligned}
& p_{c}\left(t, k_{2}, \omega_{2}, \gamma_{2}\right)=A\left[\left(1-\exp \left(-\gamma_{2} t\right)\right) \cos \left(\omega_{2} t-\varphi\right)+g\left(t, k_{2}, \omega_{2}, \gamma_{2}\right)\right] \\
& p_{d}\left(t, k_{1}, \omega_{1}, \gamma_{1}, k_{2}, \omega_{2}, \gamma_{2}\right)=B\left[p_{c}\left(t, k_{2}, \omega_{2}, \gamma_{2}\right)-p_{c}\left(t, k_{1}, \omega_{1}, \gamma_{1}\right)\right] \\
& \varphi\left(k_{2}, \omega_{2}, \gamma_{2}\right)=\arctan \left(\frac{1+k_{2} / 2 Q_{2}+3 / 4 Q_{2}}{1+k_{2}-3 / 4 Q_{2}}\right)
\end{aligned}
$$

where $\omega_{1,2}, \gamma_{1,2}, Q_{1,2}$ are frequencies, dissipation coefficients and qualities of the above-mentioned PA cell resonances, $k_{1,2}=\beta \mu\left(\omega_{1,2}\right), \beta$ is optical absorption coefficient to be measured, $\mu(\omega)=(2 \chi / \omega)^{1 / 2}$ is thermal diffusion length, with $\chi$ being thermal diffusivity of the sample, $g\left(t, k_{2}, \omega_{2}, \gamma_{2}\right)$ is monotonously increasing function which can be expressed in terms of error function and Fresnel integrals. It describes diffusion of heat to sample surface and hence vanishes as $\beta \rightarrow \infty$. Factors $A$ and $B$ are independent of time. We treat these factors as non-significant for future analysis. Eq.(1) and $\mathrm{Eq} .(2)$ are accurate to the first order in $Q_{1,2}^{-1}$.

It is clear from Eq.(1) and Eq.(2) that for fixed characteristics of PA cell such parameters of PA signal as rise time and ratios of subsequent maximum and minimum values of amplitude depend only on the product $\beta \mu\left(\omega_{2}\right)$. Hence we can use these parameters to determine $\beta$ for sample with known $\chi$ without any extra measurements of optical radiation intensity and sample characteristics. 


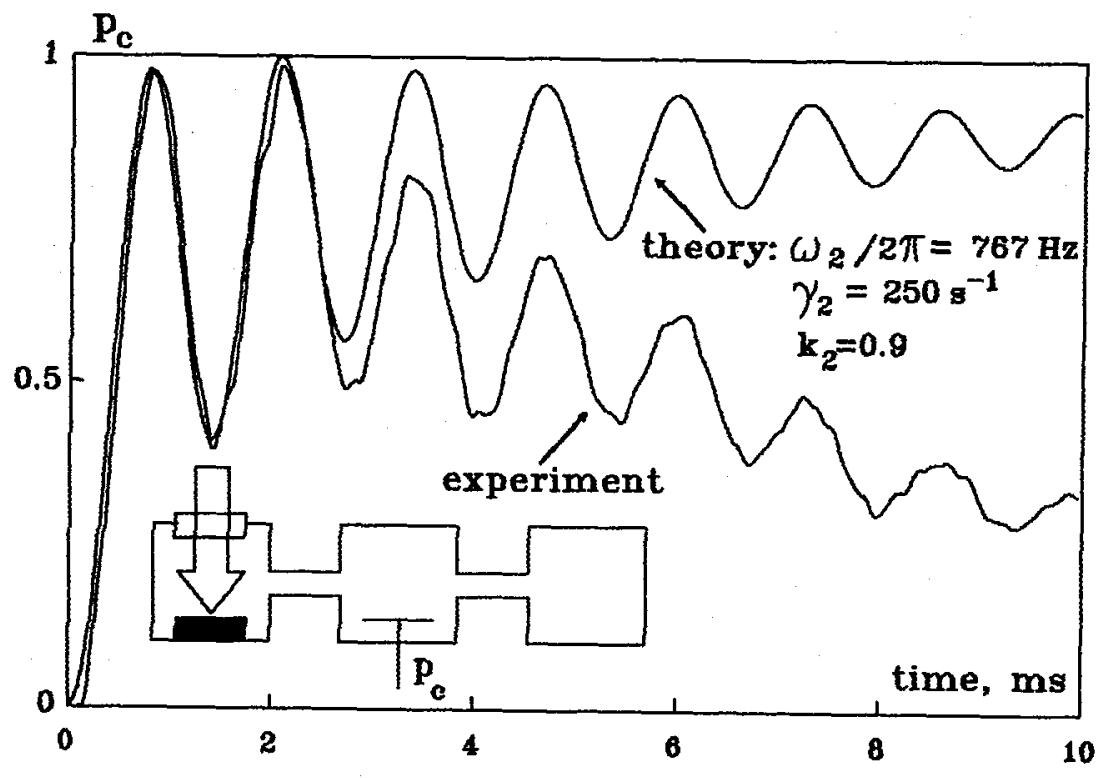

Figure 2: PA signal $p_{c}$ (a.u.) versus time excited in the central chamber of the PA cell.

The calculated PA signal, expected in central chamber of PA cell, is shown in Fig.1 as a function of time for photoacoustically transparent $\left(k_{2}=0.1\right)$ and photoacoustically opaque $\left(k_{2}=10\right)$ samples. Decreasing of $\beta$ leads to increase of rise time and causes a delay in transition to a steady state. Comparison of curves presented at Fig. 1 allows to determine parameters the most sensitive to change in $\beta: \zeta=\tau-0.25$ with $\tau$ being rise time in units of $T_{2}$ and $\xi$ is the ratio of the first maximum and the first minimum of PA signal amplitude. Numerical analysis of Eq.1 shows that these measuring parameters are optimal according to minimum value of error $\epsilon$ in determination of $\beta$ for given level of noise: $\epsilon=3 \%$ if we measure $\zeta$ with absolute error 0.001 and $\epsilon=2 \%$ for measuring $\xi$ with an error of $1 \%$. In both cases optimal value of $\omega_{2}$ for making measurements is evaluated from the following equation: $\beta \mu\left(\omega_{2}\right) \approx 1$. For measuring parameter $\zeta$ it can be derived from Eq.(1), neglecting influence of $g\left(t, k_{2}, \omega_{2}, \gamma_{2}\right)$ and dissipation $\left(\gamma_{2}=0\right)$ as well, the following expression for estimation of absorption coefficient: $\beta \approx\left(\tan ^{-1}(2 \pi \xi)-1\right) / \mu\left(\omega_{2}\right)$. The same analysis was made for the difference of PA signals in central and lateral chambers $p_{d}$. Optimal measuring parameters in this case are rise time and ratio of the first minimum and the second maximum of PA response record.

\section{MEASURING PROCEDURE: STEP-BY-STEP}

Measuring procedure consists of the following steps: (i) recording of PA signal generated in central chamber of PA cell $p_{c}$ or difference of PA signals in central and lateral chambers $p_{d}$ with selection according to maximum of signal/noise; (ii) measurement of one of the parameters of PA signal described above (for $p_{c}$ : $\zeta$ or $\xi$ ); (iii) determination of optical absorption coefficient using relationship between $\beta$ and chosen measuring parameter obtained numerically using Eq.(1) or Eq.(2).

\section{EXPERIMENTAL RESULTS AND DISCUSSION}

We examined in experiment possibility of using presented pulsed PAS technique for measuring $\beta$. We utilize water as a sample, because its thermal and optical properties are well known and $\mathrm{CO}_{2}$ laser as a radiation source. We utilize three-chamber PA cell [5] with following parameters: internal 
volume of central and lateral chambers are $2.2 \mathrm{sm}^{3}$ and $8.8 \mathrm{sm}^{3}$ respectively. Length and diameter of the inter-chamber channels are $5 \mathrm{sm}$ and $4 \mathrm{~mm}$. Calculated frequency resonances $\omega_{1} / 2 \pi=270 \mathrm{~Hz}$, $\omega_{2} / 2 \pi=810 \mathrm{~Hz}$ are in agreement with experimental data. Parameters of three-chamber PA cell were chosen in accordance with the following condition of optimal measuring regime: $\beta \mu\left(\omega_{2}\right) \approx 1$. We utilize laser pulse of low intensity (increase of sample surface temperature $\sim 1^{\circ} \mathrm{C}$ in order to provide linear regime of generation and suppress contribution of evaporation. PA response measured by the microphone in the central chamber of the PA cell is presented in Fig.2. Disagreement with theoretical curve for large interval of time is explained by the variations in frequency response of a microphone near $\sim 10 \mathrm{~Hz}$. This complicates interpretation of PA signal. The influence of the variations in a microphone frequency response can be significantly reduced by measuring difference of PA signals in central and lateral chambers because its spectrum vanishes for $\omega<\omega_{1}$ and typical value of $\omega_{1} \ll 10 \mathrm{~Hz}$. We measured different amplitude-time parameters of PA signals $p_{c}, p_{d}$ and using their relationships with $\beta$ calculated optical absorption coefficient. The mean value of $\beta=1200 \pm 100 \mathrm{~cm}^{-1}$ obtained in experiment is in agreement with literature value $[6]: \beta=1080 \mathrm{~cm}^{-1}$.

Theoretical and experimental analysis of proposed pulsed PAS technique allows to make following conclusions: (i) it can be used for both optically opaque and transparent materials; (ii) there is no need in any additional measurements; (iii) reference or calibration sample is not used.

\section{References}

[1] Wetsel G.C., McDonald F.A., Appl. Phys. Lett., 30 (1977) 252-254.

[2] Teng Y.C., Royce B.S., J. Opt. Soc. Am., 70 (1980) 557-560.

[3] Rosencwaig A., Gersho A., J. Appl. Phys., 80 (1976) 64-69.

[4] Egerev S.V., Lyamshev L.M., Puchenkov O.V., Sov. Phys. Usp., 33 (1990) 739-762.

[5] Pashin A.E., Fokin A.V., Acoust. Phys., 39 (1993) 715-723.

[6] Zolotaryov V.M. et.al., Handbook of Optical Constants, (Chemistry Publishers, Leningrad, 1984

(in Russian)) 